Revista de Economia Política, vol. 30, no 2 (118), pp. 233-253, abril-junho/2010

\title{
Crescimento econômico e liquidez externa no Brasil após 1970
}

\author{
FABRÍCIO DE ASSIS C. VIEIRA* \\ MÁRCIO HOLLAND**
}

Economic growth and foreign liquidity in Brazil after 1970. This paper assesses the relationship between the capital account and the Brazilian economic growth according to balance-of-payments constraint approach. The Thirlwall (1979)'s simple rule is extended to take into consideration capital account and several empirical evidence using time series analysis are shown. Conversely to the simple rule when fitted rates of balance-of-payment equilibrium economic growth average bellow the observed ones, fitted rates of growth using the rule extended to international liquidity are consistently greater than the observed ones. It is fair to conclude that, first, the Brazilian economy grows better during abundant international liquidity and, second, the economy sub utilizes such advantage growing far less than it could grow.

Keywords: economic growth; international liquidity; Thirlwall law; Brazilian economy.

JEL Classification: E32; O16; C32.

\section{INTRODUÇÃO}

A literatura econômica que estuda as relações entre fluxos de capitais e o crescimento econômico é bastante divergente, seja em seus resultados empíricos, seja em sua abordagem teórica. Muito convencionalmente, diz-se que a taxa de investimento doméstico aumenta em função do uso de poupança externa. A ideia

\footnotetext{
* Doutorando em Teoria Econômica pelo Centro de Desenvolvimento e Planejamento Regional (Cedeplar) da Universidade Federal de Minas Gerais (UFMG). E-mail: fvieira@cedeplar.ufmg.br.;

* Professor da Escola de Economia de São Paulo da Fundação Getulio Vargas (FGV-EESP). O autor agradece o generoso suporte financeiro do CNPq. E-mail: marcio.holland@fgv.br.

Os autores agradecem aos pareceristas anônimos pelos seus valiosos comentários e sugestões de revisão de versão submetida originalmente. Submetido: Agosto 2007; Aprovado: Outubro 2008.
} 
subjacente a este argumento é que economias não desenvolvidas, com baixo nível de poupança doméstica e escassez de capital (baixa razão capital-trabalho), se beneficiariam do ingresso de capitais, devido ao fato de que os retornos ao capital são maiores em economias desse tipo.

Argumentos que vão contra tal literatura convencional podem ser vistos em Gourinchas e Jeanne (2006) e Aghion et al. (2006). Gourinchas e Jeanne (2006) consideram que as causas para os baixos níveis de renda per capita dos países pobres estariam na baixa produtividade e nas maiores distorções nessa produtividade, e não na baixa razão capital-trabalho. O acesso ao capital externo por si só não poderia gerar mais crescimento adicional em países pobres ou menos desenvolvidos, tornando necessário melhorias na produtividade nesses países com o intuito de atrair capitais externos. Já Aghion et al. (2006) consideram que a presença de poupança doméstica seria de fundamental importância para um país atrair poupança externa.

Fora do eixo da literatura econômica mais tradicional, tem-se a contribuição de Thirlwall $(1979,1991)$, que recupera o lado da demanda agregada na explicação do crescimento econômico dos países. Thirlwall (1979) apresentou um modelo de crescimento econômico que leva em conta as restrições presentes no balanço de pagamentos - restrições advindas de elasticidades-renda desfavoráveis. A ideia é que as causas para as diferenças nas taxas de crescimento entre os países estão ligadas a diferenças nas taxas de crescimento da demanda e não devido à acumulação de estoques de capital (físico e humano), tecnologia e outros fatores ligados à oferta (McCombie \& Thirlwall, 1994).

De acordo com esta abordagem, nos países periféricos, incluindo o Brasil, a maior restrição sobre a taxa de crescimento da demanda seria o Balanço de Pagamentos (BP), que expressa a relação entre a demanda externa pelas exportações e a demanda interna pelas importações. Dentro desta abordagem, a restrição externa tem importância fundamental no crescimento de países como o Brasil e outros latino-americanos, que ainda apresentam uma desfavorável relação entre a elasticidade-renda da demanda por importações e a elasticidade-renda da demanda por exportações, apesar de importantes mudanças na pauta de exportações.

Nesse sentido, Thirlwall (1991) considera que países que produzem e exportam bens primários (e/ou menos elaborados tecnologicamente) terão uma restrição em seu crescimento (em relação aos países mais industrializados) devido ao desequilíbrio no balanço de pagamentos. Nesse sentido, na ausência de mudanças na pauta de exportações ou nos termos de troca, aliado a uma escassez de recursos externos, o crescimento econômico desses países em desenvolvimento se torna restringido pelo balanço de pagamentos.

Thirlwall e Hussain (1982) foram os primeiros a incorporar a variável fluxo de capitais ao modelo original de Thirlwall, em estudo para vários países em desenvolvimento. Segundo Thirlwall e Hussain, a maioria destes países ${ }^{1}$ incorria em

\footnotetext{
${ }^{1}$ Thirlwall e Hussain (1982) e Thirlwall (2005) consideram também que a experiência de crescimento
} 
déficits em conta corrente financiados por capitais externos, o que, até certo ponto, não comprometeria o equilíbrio do balanço de pagamentos. A ideia destes autores é que na ausência dos capitais externos a restrição ao crescimento se torna ainda maior, pois nos países em desenvolvimento "in general foreign exchange is a more acute bottleneck than in the developed countries" (ibid., p. 500). Em contrapartida, Bresser-Pereira (2006) mostra claramente como o crescimento econômico via uso de poupança externa tem como consequência imediata a apreciação real da moeda doméstica levando a economia a experimentar a quase estagnação.

Evidências empíricas de Thirlwall e Hussain (1982) para o Brasil no período 1951-1969 mostram que com a introdução dos capitais externos à regra simples, a taxa média estimada de crescimento da renda passou de $4 \%$ a.a. para $9,4 \%$ a.a, sendo que a taxa observada de crescimento foi de 9,5\% a.a. no período 1951-1969, ou seja, a contribuição da variável fluxo de capitais na explicação da taxa estimada de crescimento foi de $5,4 \%$.

Elliott e Rhodd (1999) incorporaram ao modelo estendido de Thirlwall e Hussain os efeitos dos serviços da dívida sobre a taxa de crescimento da renda, uma vez que estes autores consideram que os desvios observados entre a taxa média estimada e a taxa média observada de crescimento da renda segundo este modelo estendido não podem ser explicados somente pelos efeitos adversos ou favoráveis decorridos de mudanças nos preços relativos. Elliott e Rhodd consideram que a omissão dos efeitos causados pelo pagamento dos serviços da dívida seria a causa para a persistência dos desvios entre as taxas estimadas e observadas de crescimento da renda, uma vez que a entrada dos capitais externos, que serve para equilibrar o BP gera, por outro lado, uma restrição adicional de demanda, decorrente do pagamento do serviço da dívida. No entanto, a evidência empírica destes autores para a economia brasileira no período 1951-1969 mostra uma subestimação da taxa de crescimento da renda, ou seja, a taxa estimada com a inclusão do serviço da dívida foi de $6,6 \%$ a.a., ao passo que a taxa observada foi de 9,5\% a.a. Assim, para o caso brasileiro, a inclusão da variável pagamento dos serviços da dívida ao modelo estendido não contribuiu para uma melhor explicação da taxa de crescimento da renda segundo a abordagem de crescimento considerada.

Ferreira e Canuto (2001) analisaram o papel desempenhado pelos pagamentos líquidos de juros, dividendos e lucros do capital externo sobre as restrições do BP ao crescimento econômico brasileiro. $\mathrm{O}$ argumento destes autores para a introdução destas variáveis ao modelo de Thirlwall e Hussain é que os influxos líquidos de capitais desempenharam um duplo papel no crescimento econômico brasileiro no período 1949-1999. Assim, se por um lado o influxo de capitais contribuiu para financiar o crescimento brasileiro neste período, por outro lado estes capitais acarretaram um pagamento relativo aos serviços da dívida. Os resultados de Fer-

dos países em desenvolvimento tem sido mais diversa do que a dos países desenvolvidos, e que dificilmente pode ser explicada fazendo-se referência à taxa autônoma de crescimento dos fatores de oferta. Os autores consideram que a acumulação de capital, a oferta de trabalho e o progresso tecnológico são parcialmente endógenos ao sistema econômico e respondem a variações de pressão na demanda. 
reira e Canuto mostraram que, enquanto o crescimento econômico médio da economia brasileira foi de 5,41\% a.a. em 1949-1999, o crescimento estimado via regra simples foi de 6,18\% a.a. e pela "Financial Simple Rule" foi de 5,23\% a.a. Assim, as estimativas realizadas por Ferreira e Canuto mostraram que o modelo que incorpora os pagamentos líquidos de juros, dividendos e lucros do capital externo ("Financial Simple Rule") se adequou melhor ao caso brasileiro no período 1949-1999, em comparação com os modelos de Thirlwall e Hussain (1982) e Elliott e Rhodd (1999).

Santos et al. (2005) estimaram, para o período 1948-2004, a elasticidade-renda efetiva da demanda por importações e as elasticidades-renda hipotéticas de acordo com a regra simples e de acordo com o modelo descrito em Moreno-Brid (2003), que leva em conta o pagamento de juros e o fluxo de capitais. Os resultados empíricos de Santos et al. mostram que tanto a versão do modelo expressa pela regra simples quanto a versão oriunda de Moreno-Brid se adequaram ao caso brasileiro no período considerado. Por outro lado, estudo de Lima e Carvalho (2007), também para a economia brasileira, nos períodos 1931-1993 e 1994-2004 mostram que o crescimento brasileiro foi àquele compatível com o equilíbrio do $\mathrm{BP}$, mas os fluxos de capitais tiveram pouca ou nenhuma contribuição para esse crescimento. Enquanto a contribuição dos fluxos de capitais foi de $0,02 \%$ em 1994-2004, no período 1931-1993 tal variável não teve nenhuma contribuição para o crescimento do PIB brasileiro.

Este trabalho analisa a abordagem do crescimento com restrição externa para a economia brasileira no período 1971-2005, com ênfase no papel dos fluxos de capitais externos no financiamento do crescimento econômico brasileiro. Conforme veremos na seção seguinte, o desempenho econômico brasileiro no período analisado acompanhou a evolução dos fluxos de capitais externos, representado pelo Inverso do Saldo em Conta Corrente e pelo Saldo da Conta Capital e Financeira. Assim, espera-se demonstrar que o crescimento econômico brasileiro no período 1971-2005 apresentou fortes restrições externas, e que os fluxos de capitais externos contribuíram para a explicação do crescimento econômico brasileiro nesse período. Contudo, os resultados empíricos aqui apresentados mostram que as taxas de crescimento de equilíbrio do balanço de pagamentos em modelo com conta de capital são maiores do que as taxas observadas. Pode-se, assim, inferir que o país subutilizou, em grande medida, o ambiente de maior liquidez internacional.

$\mathrm{O}$ trabalho está dividido em quatro seções, além desta introdutória. $\mathrm{Na}$ segunda seção é feita uma sumária apresentação de fatos e experiências da economia brasileira; na terceira seção é apresentado o modelo extendido de crescimento desenvolvido por Thirlwall para incorporar a conta de capital. Na quarta seção serão apresentados os resultados empíricos conforme pesquisa em séries temporais para o período posterior a 1970. Por fim, a última seção se dedica às considerações finais. 


\section{FLUXOS DE CAPITAIS E CRESCIMENTO: A EXPERIÊNCIA BRASILEIRA}

Nos anos 1970, o Brasil e outras economias latino-americanas passaram por um período de alta liquidez internacional e crescente entrada de capitais externos. A expansão dos bancos transnacionais e os petrodólares, surgidos logo após o choque do petróleo em 1973, serviram como importante fonte de financiamento para as economias emergentes, incluindo o Brasil. No cenário externo, pode-se destacar nesse período o aumento da inflação em diversos países do mundo, a consequente elevação das taxas de juros internacionais e a adoção de políticas fiscais e monetárias restritivas de contenção de demanda.

É nesta década que podemos dizer que o padrão de crescimento brasileiro passou por algumas mudanças significativas, em direção a um padrão de crescimento cada vez mais dependente dos recursos externos ("crescimento com endividamento"). Nesse sentido, quando se compara o padrão de crescimento brasileiro desde o Plano de Metas até o início do "Milagre", verifica-se que, apesar do tratamento preferencial dado ao capital estrangeiro e dos desequilíbrios no Balanço de Pagamentos, o padrão de crescimento brasileiro ainda era baseado em forte iniciativa estatal, com ênfase na política de substituição de importações e pouca recorrência ao capital externo. Já a partir da segunda metade dos anos 1960 houve mudanças no padrão de crescimento brasileiro, com substancial aumento da capacidade para importar e uma política mais voltada para o incentivo ao ingresso dos capitais estrangeiros.

Não obstante essas mudanças, no período 1974-1980, não houve no Brasil uma política de liberalização das importações, vis-à-vis uma maior disponibilidade de recursos externos. De acordo com Bielschowsky (2000), nesse período, o Brasil optou pela substituição de importações, incentivo às exportações e investimento em infraestrutura energética e industrial, destacando-se a produção de petróleo, as indústrias de base e de bens de capital. ${ }^{2}$

Em termos numéricos, o aumento da participação dos capitais externos no Brasil pode ser observado através do Gráfico 1, adiante, que mostra as evoluções do Saldo da Conta Capital e Financeira e do Inverso do Saldo em Conta Corrente. De uma média anual extremamente baixa de US\$ 233,5 milhões no período 1950-1967, o saldo da conta capital e financeira atinge US\$ 680 milhões em 1968, saltando para uma média de US\$ 6.300 milhões no período 1968-1982. No que tange ao desempenho econômico, conforme tabela abaixo, o crescimento médio anual do PIB brasileiro passa de 6,3\% no período $1950-1967$ para $7,5 \%$ no período 1968-1982 - com destaque para o crescimento médio de $11,5 \%$ a.a. no período do "Milagre econômico".

\footnotetext{
${ }^{2}$ De fato, o II Plano Nacional de Desenvolvimento (II PND) implementado no Brasil no período 1979-1983 pretendia dar continuidade ao crescimento econômico, evitando que o primeiro choque do petróleo desestabilizasse a economia. Castro e Souza (1985) consideram que o II PND foi responsável por mudanças estruturais na economia brasileira, com estímulo à substituição de importações nos setores de bens de capital e insumos básicos para a indústria.
} 
Tabela 1: Valores médios (Milhões de Dólares) do Saldo da Conta Capital e Financeira, Inverso do Saldo em Conta Corrente e Taxa de Crescimento do PIB (\%), por períodos

\begin{tabular}{|l|c|c|c|c|c|}
\hline & $1950-1967$ & $1968-1982$ & $1983-1996$ & $1997-2005$ & $1950-2005$ \\
\hline $\begin{array}{l}\text { Saldo Conta Capital } \\
\text { e Financeira }\end{array}$ & 233,5 & 6299,6 & 8165,6 & 12799,7 & 5860,9 \\
\hline $\begin{array}{l}\text { Inverso Saldo Conta } \\
\text { Corrente }\end{array}$ & 204,8 & 6090,2 & 3709,3 & 12692,1 & 4664,3 \\
\hline Taxa Crescimento PIB & 6,3 & 7,5 & 2,7 & 2,1 & 5,0 \\
\hline
\end{tabular}

Fonte: Elaboração própria a partir de dados do IPEADATA e Banco Central do Brasil.

Assim, à primeira vista, pode-se dizer que o desempenho econômico brasileiro acompanhou o aumento na liquidez externa. A taxa de crescimento do PIB aumenta a partir de 1968, juntamente com o aumento dos recursos externos, declinando no fim do período do "Milagre", mas ainda com uma média de $5 \%$ a.a. até o fim do período de queda na liquidez externa (1982). ${ }^{3}$ Assim, apesar da desaceleração industrial, alta inflação, dos déficits públicos e dos problemas no BP, a economia brasileira apresentou altas taxas de crescimento nos anos 1970, que só foram interrompidas no triênio 1981-1983, aliado a uma queda na liquidez externa.

Se, nos anos 1970, o Brasil assistiu a um período de elevada liquidez internacional, que contribuiu significativamente para o financiamento de seu crescimento, na década de 1980 o país enfrentou a falta de financiamento internacional, e conviveu com desequilíbrios no balanço de pagamentos, alta inflação, alto serviço da dívida externa e o alarmante crescimento dos déficits públicos, o que gerava desequilíbrios internos e externos. Os choques do petróleo e a elevação dos juros internacionais, na década de 1970, contribuíram para uma expressiva queda de mais de $4 \%$ do PIB brasileiro no ano de 1981, sendo que a taxa média anual de crescimento do PIB nesta década foi de apenas 1,7\% a.a. Conforme se verifica através do Gráfico 1 acima, o Saldo da Conta Capital e Financeira que apresentava tendência ascendente no triênio 1979-1981, já no ano de 1982 apresenta reversão de tendência, com uma queda substancial em 1983. Em termos de desempenho econômico, o severo ajuste recessivo impedia o crescimento do PIB brasileiro, através da contenção da demanda por importações. Na verdade, como o objetivo era o de sanear o balanço de pagamentos e reduzir a inflação, houve uma contração da demanda interna, através da redução do consumo e do investimento, o que permitiu o deslocamento da produção para o mercado externo.

Por sua vez, na década de 1990, se verifica o retorno ao financiamento internacional, no contexto de baixas taxas de juros nos países avançados (1990-1993), fazendo com que os capitais migrassem para os emergentes (como o Brasil), globalização acelerada do sistema financeiro e de capitais, planos de estabilização bem-su-

\footnotetext{
${ }^{3}$ A entrada líquida de capitais externos no período do "Milagre econômico" até o ano de 1981, via empréstimos em moeda, parece ter sido a principal modalidade de financiamento de longo prazo da economia brasileira. A esse respeito, ver Mendes (1993).
} 
cedidos na Argentina, México e Chile, e Plano Brady de reciclagem da dívida externa dos países em desenvolvimento. Neste contexto, observa-se uma crescente entrada de capitais externos em países emergentes, incluindo o Brasil. Assim, o Saldo da Conta Capital e Financeira salta de US\$ 163 milhões em 1991 para US\$ 9.947 milhões no ano de 1992, mantendo uma média anual de US\$ 18.439 milhões até 1996, quando então sofre uma queda a partir de 1997 (Crise Asiática).

Gráfico 1: Brasil - Saldo da Conta Capital e Financeira e Inverso do Saldo em Conta Corrente (1960-2005) — Milhões de dólares

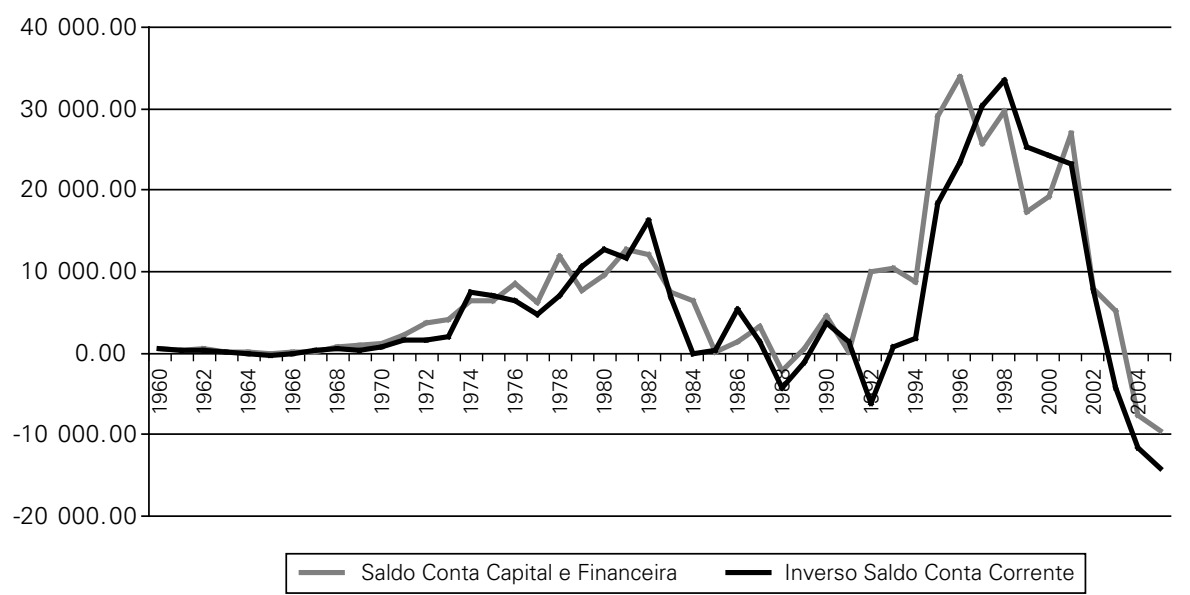

Fonte: Boletim do Banco Central do Brasil e IPEADATA.

No que tange ao desempenho econômico brasileiro, o crescimento médio do PIB de 4,4\% a.a. no triênio 1993-1996 foi acompanhado de um aumento na liquidez externa. Contudo, já a partir de 1998 e até o ano de 2003, a economia brasileira apresentou baixas taxas de crescimento econômico (excetuando-se o ano de 2000), concomitante a uma queda nos recursos externos que se agravou no biênio 2004-2005. Ou seja, na década de 1990, como também ocorreu nas décadas de 1970 e 1980, o desempenho econômico brasileiro acompanhou de certa forma a evolução positiva na liquidez internacional, expresso pelo Saldo da Conta Capital e Financeira e pelo Inverso do Saldo em Conta Corrente.

Contudo, o crescimento brasileiro na década de 1990 não foi tão expressivo, como nos anos 1970, apesar da volta dos recursos externos à economia brasileira, mesmo que superior ao crescimento médio observado nos anos 1980.

\section{MODELO EXPANDIDO DE THIRLWALL}

Seguindo Thirlwall e Hussain (1982), se o balanço de pagamentos apresenta inicialmente um desequilíbrio na conta corrente, podemos expressar a seguinte relação: 


$$
\theta\left(p_{d}+x\right)+(1-\theta) f=p_{f}+m+e
$$

em que $x$ é a taxa de crescimento das exportações, $m$ é a taxa de crescimento das importações, $P_{d}$ é o preço doméstico das exportações, $P_{f}$ é o preço externo das importações, $e$ é a taxa de variação do câmbio nominal, $f$ representa a taxa de crescimento do fluxo nominal de capitais medido em moeda doméstica. Por sua vez, $\theta$ e $1-\theta$ representam, respectivamente, a parcela das exportações na receita total para custear as importações e a parcela dos capitais externos na receita total para custear as importações.

A função de demanda por exportações relaciona o volume demandado de exportações com os preços relativos, medidos em moeda comum, e com a renda mundial. Já a função de demanda por importações pode ser descrita como uma equação que relaciona as importações com a competitividade e com a renda doméstica. Em termos de taxas de crescimento das variáveis e assumindo elasticidade constante, as funções de demanda por exportações e importações podem ser descritas como:

$$
\begin{aligned}
& x=\eta\left(p_{d}-p_{f}-e\right)+\varepsilon(z) \\
& m=\psi\left(p_{d}-p_{f}-e\right)+\pi(y)
\end{aligned}
$$

Nas equações acima, $z$ é a taxa de crescimento da renda mundial, $y$ é a taxa de crescimento da renda doméstica, $\left(p_{d}-p_{f}-e\right)$ é a taxa de crescimento dos preços relativos, $\eta(<0)$ é a elasticidade-preço da demanda por exportações, $\varepsilon(<0)$ é a elasticidade-renda da demanda por exportações, $\psi(<0)$ é a elasticidade-preço da demanda por importações e $\pi(<0)$ é a elasticidade-renda da demanda por importações.

Por sua vez, a taxa de crescimento da economia com restrição no balanço de pagamentos, começando com um desequilíbrio em conta corrente, é obtida através da substituição das equações (2) e (3) em (1), de modo a obtermos: ${ }^{4}$

$$
y_{b h}=\frac{\left[(\theta \eta+\psi)\left(p_{d}-p_{f}-e\right)+\left(p_{d}-p_{f}-e\right)+\theta x+(1-\theta)\left(f-p_{d}\right)\right]}{\pi}
$$

em que $\left(f-p_{d}\right)$ é o crescimento real dos capitais externos (medidos em moeda nacional). A ideia presente neste modelo que incorpora o fluxo de capitais externos é que o crescimento de longo prazo de países em desenvolvimento passa a ser res-

\footnotetext{
${ }^{4}$ Seguindo Thirlwall e Hussain (1982), iremos considerar que o produto entre a elasticidade-renda da demanda por exportações e a taxa de crescimento da renda mundial é igual à taxa de crescimento das exportações domésticas: "Since we do not have information on $\varepsilon\left(z_{t}\right)$ for all countries we shall assume that $\varepsilon\left(z_{t}\right)=x_{t}$, thereby incorporating into the analysis from the start any volume changes in exports from relative price movements" (Thirlwall e Hussain, 1982, p. 503).
} 
tringido também pela evolução dos capitais externos, além das exportações líquidas e dos termos reais de troca.

Seguindo Thirlwall (2005), podemos decompor a taxa de crescimento de qualquer país nos quatro componentes abaixo:

a) primeiro termo $(\theta \eta+\Psi)\left(p_{d}-p_{f}-e\right)$ indica o efeito do volume das alterações dos preços relativos;

b) segundo termo $\left(p_{d}-p_{f}-e\right)$ fornece o efeito puro dos termos de troca sobre o crescimento da renda real;

c) termo $\theta(x)$ ou $\theta \varepsilon(z)$ mostra o efeito de mudanças exógenas na taxa de crescimento da renda internacional; 5

d) quarto termo $(1-\theta)\left(f-p_{d}\right)$ indica o efeito do crescimento das entradas reais de capital que financiam o crescimento que ultrapassa o crescimento compatível com o equilíbrio em conta corrente do BP.

Se considerarmos que os preços relativos permanecem constantes no longo prazo, a equação (4) se torna:

$$
y_{b h^{*}}=\frac{\left[\theta(x)+(1-\theta)\left(f-p_{d}\right)\right]}{\pi}
$$

Ou seja, a taxa de crescimento da economia com restrição no BP, com um desequilíbrio inicial em conta corrente, é a soma ponderada do crescimento das exportações (devido ao crescimento exógeno da renda mundial) e do crescimento do fluxo real de capitais, dividido pela elasticidade-renda da demanda por importações $(\pi)$. Agora, caso se adote a suposição de que os preços relativos são constantes e se os fluxos de capitais não exercem grande influência na taxa de crescimento de longo prazo da economia, a equação (5) se transforma na conhecida regra simples de Thirlwall:

$$
y_{b p}=x / \pi
$$

\section{Versão Moreno-Brid ${ }^{6}$}

Em estudo para a economia mexicana, Moreno-Brid (2003) incluiu a variável pagamento líquido de juros internacionais ao exterior e trabalhou com a hipótese de que a acumulação de endividamento externo não apresenta um comportamento

\footnotetext{
${ }^{5}$ Assumindo-se que $\varepsilon(z)=x$.

${ }^{6}$ Moreno-Brid (2003) não foi o único a estender o modelo de Thirlwall e Hussain (1982) e incluir outras variáveis e restrições a este modelo. Entre outros, podemos citar os trabalhos de Elliott e Rhodd (1999), quem incorporaram os efeitos dos serviços da dívida sobre a taxa de crescimento da renda, McCombie e Thirlwall (1997), quem adicionaram a restrição de manutenção da relação dívida sobre PIB, Ferreira e Canuto (2001), quem analisaram o papel desempenhado pelos pagamentos líquidos de juros, dividendo e lucros do capital externo sobre as restrições do Balanço de Pagamentos, Barbosa-Filho (2001), que introduziu o problema do endividamento no BP e a separação entre pagamento de juros da dívida e importação e exportação de bens e serviços não fatores.
} 
explosivo, tal que a razão entre o déficit em conta corrente e a renda interna se mantém constante no longo prazo. Em termos de crescimento, as funções de demanda por importações e exportações no modelo de Moreno-Brid (2003) podem ser representadas pelas seguintes equações: ${ }^{7}$

$$
\begin{aligned}
& \frac{d x}{x}=\eta\left(\frac{d p}{p}-\frac{d p^{*}}{p^{*}}\right)+\varepsilon \frac{d w}{w} \\
& \frac{d m}{m}=\psi\left(\frac{d p^{*}}{p^{*}}-\frac{d p}{p}\right)+\pi \frac{d y}{y}
\end{aligned}
$$

em que $p$ *são os preços externos, $m$ são as importações reais, $p$ representa os preços domésticos, $x$ as exportações reais, $w$ representa a renda real mundial, $\eta$ é a elasticidade-preço da demanda por exportações, $\varepsilon$ é a elasticidade-renda da demanda por exportações, $\psi$ é a elasticidade-preço da demanda por importações e $\pi$ é a elasticidade-renda da demanda por importações. A expressão dinâmica da identidade do Balanço de Pagamentos pode ser representada pela seguinte equação:

$$
\frac{d p^{*}}{p^{*}}+\frac{d m}{m}=\theta_{1}\left(\frac{d p}{p}-\frac{d x}{x}\right)-\theta_{2}\left(\frac{d r}{r}+\frac{d p}{p}\right)+\left(1-\theta_{1}+\theta_{2}\right)\left(\frac{d f}{f}+\frac{d p}{p}\right)
$$

em que $r$ corresponde ao pagamento líquido de juros ao exterior, medido em termos reais, o produto $p f=F$ representa o influxo líquido de capital externo medido em unidades de moeda local.

Já a proporção do gasto com importações que é coberto pelas receitas de exportação $\left(\theta_{1}>0\right)$ e a proporção do pagamento líquido de juros ao exterior, em relação ao gasto com importações $\left(\theta_{2}>0\right),{ }^{8}$ podem ser representados pelas seguintes equações:

$$
\begin{aligned}
& \theta_{1}=p x / p^{*} m \\
& \theta_{2}=p r / p^{*} m
\end{aligned}
$$

Por sua vez, a identidade do Balanço de Pagamentos implícita na equação (9) pode ser representada como $M=X-R+F$, em que $M$ e $X$ são, respectivamente, o total das importações e o total das exportações, $R$ é o total do pagamento líquido de juros ao exterior e $F$ é o déficit em conta corrente, que será financiado pelo influxo líquido de capital externo. Moreno-Brid (2003) considera que a razão entre o déficit em conta corrente e o PIB é estável, ou seja:

$$
F / Y=k
$$

\footnotetext{
${ }^{7}$ As letras minúsculas denotam variáveis medidas em preços constantes; asteriscos denotam variáveis medidas em preços externos. A notação $d m / m$ denota a taxa de crescimento da variável $\mathrm{m}$. A taxa nominal de câmbio é considerada fixa e igual à unidade.

${ }^{8} \mathrm{O}$ fato de $\theta_{2}$ ser maior do que zero indica que o país é um devedor líquido. Conforme Moreno-Brid (2003), ambas as parcelas $\theta_{1}$ e $\theta_{2}$ devem ser medidas no início do período de análise.
} 
Nesta expressão, $k$ é uma constante. Considerando, pela definição, que $F=p f$ e $Y=p y$, a equação (12) é equivalente à:

$$
\frac{d f}{f}+\frac{d p}{p}=\frac{d y}{y}+\frac{d p}{p}
$$

Então, resolvendo o sistema de equações (7) a (11) e (13), chega-se à expressão da taxa de crescimento da economia compatível com o equilíbrio do BP, que capta a influência do pagamento de juros ao exterior e garante uma trajetória de longo prazo sustentável de acumulação da dívida externa:

$$
y=\frac{\theta_{1} \varepsilon d w / w-\theta_{2} d r / r+\left(\theta_{1} \eta+\psi+1\right)(d p / p-d p * / p *)}{\pi-\left(1-\theta_{1}+\theta_{2}\right)}
$$

No caso em que a variação dos termos de troca é insignificante, temos que:

$$
y_{m b}=\frac{\theta_{1} d x / x-\theta_{2} d r / r}{\pi-\left(1-\theta_{1}+\theta_{2}\right)}
$$

Se o déficit em conta corrente for zero $\left(1-\theta_{1}+\theta_{2}=0\right)$, a expressão para a taxa de crescimento da renda compatível com o equilíbrio do BP fica da seguinte forma:

$$
y_{m b^{*}}=\frac{\theta_{1} d x / x+\left(1-\theta_{1}\right) d r / r}{\pi}
$$

No caso em que o pagamento de juros é zero e considerando a razão entre as exportações e importações como $\theta_{X M}$, a equação (15) passa a ser:

$$
y_{m b^{*}}=\frac{\theta_{X M} d x / x}{\pi-\left(1-\theta_{X M}\right)}
$$

Dessa forma, após deduzir estas equações que representam as taxas de crescimento compatíveis com o equilíbrio do BP, Moreno-Brid (2003) estimou, para a economia mexicana no período 1967-1999, a elasticidade-renda real da demanda por importações e a comparou com as três elasticidades-renda hipotéticas obtidas através da regra simples e das equações (15) e (17) acima. ${ }^{9}$ Os resultados de Moreno-Brid (2003) mostraram que tanto a regra simples quanto as versões do modelo expressas pelas equações (15) e (17) se adequaram bem à economia mexicana, sendo que estas duas últimas versões se adequaram melhor em comparação à regra simples. Assim, Moreno-Brid (2003) constatou que o pagamento líquido de juros internacionais ao exterior contribuiu para um menor crescimento econômico do México no período 1967-1999.

\footnotetext{
${ }^{9}$ No caso da regra simples, representada pela equação $y_{b}=\frac{d x / x}{\pi}$, para obter a elasticidade-renda hipotética $\left(\pi_{T}\right)$, basta substituir $y_{b}$ pelo atual valor da taxa de crescimento da renda $(d y / y)$, o que nos dá a seguinte equação: $\pi_{T}=\frac{d x / x}{d y / y}$.
} 


\section{RESULTADOS EMPÍRICOS}

\section{Dados e fontes}

Para verificarmos a contribuição do fluxo de capitais para o desempenho econômico brasileiro no período 1971-2005 utilizaremos dados anuais das variáveis PIB (Produto Interno Bruto), exportações, importações, termos de troca (razão entre o valor unitário das exportações e o valor unitário das importações), capitais (representado pelo inverso do saldo em conta corrente) e pagamento líquido de juros internacionais ao exterior. As séries do PIB, exportações e importações foram obtidas na base de dados do IPEADATA, enquanto a série dos termos de troca foi obtida em Oxford Latin American Economic History Database. Já as séries de inverso do Saldo em Conta Corrente e Pagamento Líquido de Juros Internacionais ao exterior foram obtidas na base de dados do Banco Central do Brasil.

Todas as variáveis, exceto os termos de troca, estão expressas em moeda nacional a preços constantes. Foi utilizada a taxa de câmbio comercial de venda (média anual), obtida no IPEADATA, para transformar as séries - exportações, importações, capitais (Inverso do Saldo em Conta Corrente) e Pagamento Líquido de Juros Internacionais ao Exterior - que estavam em dólares para reais. Posteriormente, estas séries foram deflacionadas utilizando-se o índice geral de preços ao consumidor obtido no International Financial Statistics. Por sua vez, a variável PIB, obtida no IPEADATA, já estava expressa em moeda nacional a preços constantes, não sendo necessário nenhum procedimento de transformação.

\section{Metodologia e procedimentos}

As taxa médias de crescimento da renda brasileira no período 1971-2005 serão estimadas utilizando-se os modelos de Thirlwall e Hussain (1982) e Moreno-Brid (2003). As equações do modelo de Thirlwall e Hussain (1982) que serão usadas são as equações (4), (5) e (6), descritas na terceira seção e reescritas aqui como as equações (18) a (20):

$$
\begin{aligned}
& y_{b h} \frac{\left[(\theta \eta+\psi)\left(p_{d}-p_{f}-e\right)+\left(p_{d}-p_{f}-e\right)+\theta(x)+(1-\theta)\left(f-p_{d}\right)\right]}{\pi} \\
& y_{b h h^{*}} \frac{\left[\theta(x)+(1-\theta)\left(f-p_{d}\right)\right]}{\pi} \\
& y_{b p}=x / \pi
\end{aligned}
$$

Já as equações do modelo de Moreno-Brid (2003) que serão estimadas nesta seção são as equações (15) a (17) da terceira seção e reescritas aqui por conveniência como as equações $(21)$ a $(23):^{10}$

\footnotetext{
${ }^{10}$ Nestas equações, as parcelas $\theta, 1-\theta, \theta_{1}, \theta_{2}$ e $\theta_{\mathrm{XM}}$ devem ser medidas no início do período de análise.
} 


$$
\begin{aligned}
& y_{m b}=\frac{\theta_{1} d x / x-\theta_{2} d r / r}{\pi-\left(1-\theta_{1}+\theta_{2}\right)} \\
& y_{m b^{*}}=\frac{\theta_{1} d x / x+\left(1-\theta_{1}\right) d r / r}{\pi} \\
& y_{m b^{* *}}=\frac{\theta_{X M} d x / x}{\pi-\left(1-\theta_{X M}\right)}
\end{aligned}
$$

O procedimento econométrico a ser utilizado será a análise de cointegração, que permite o estudo conjunto das dinâmicas de curto prazo e de longo prazo entre variáveis que são cointegradas. Ou seja, espera-se verificar se as variáveis importações, PIB e termos de troca se cointegram. Seguindo Enders (1995), as séries das variáveis econômicas $\left(x_{1}, x_{2}, \ldots x_{n}\right)$ se encontram em equilíbrio de longo prazo quando $\beta_{1}, x_{1 t}+\beta_{2}, x_{2 t}+\ldots \beta_{n}, x_{n t}=0$; em que $x_{t}$ é um vetor de variáveis do modelo e $\beta$ é o vetor de cointegração. O desvio do equilíbrio de longo prazo é chamado de erro de equilíbrio $\left(\varepsilon_{t}=\beta x_{\mathrm{t}}\right)$. Considerando o componente aleatório $\varepsilon_{t}$ como estacionário e com média zero, $\beta_{1}, x_{1 t}+\beta_{2}, x_{2 t}+\ldots \beta_{n}, x_{n t}=0$ passa a ser $\beta_{1}, x_{1 t}+\beta_{2}, x_{2 t}+$ $\ldots \beta_{n}, x_{n t}=\varepsilon_{t}$, ou seja, o vetor de equilíbrio de longo prazo se torna estacionário.

Na prática, será adotado o procedimento de cointegração conforme Johansen e Juselius (1990), que permite fazer análise de cointegração entre variáveis num contexto multivariado - sistema de equações com $n$ variáveis. Contudo, antes de proceder à análise de cointegração entre as séries das importações, PIB e termos de troca, é necessário verificar a ordem de integração dessas variáveis, o que será feito através dos testes de raiz unitária Augmented Dickey-Fuller (ADF) e Phillips-Perron (PP). Como os testes ADF estão sujeitos a um viés na presença de quebras estruturais, o que pode resultar numa não rejeição da hipótese nula de raiz unitária, usa-se também o teste de Phillips-Perron com quebra estrutural.

\section{Resultados}

$\mathrm{Na}$ verificação da ordem de integração das variáveis PIB, exportações, importações, termos de troca, capitais (Inverso do Saldo em Conta Corrente) e Pagamento Líquido de Juros Internacionais ao Exterior, verifica-se que todas elas se tornaram estacionárias em primeira diferença, tanto pelo teste ADF quanto pelo teste PP com quebra estrutural. ${ }^{11}$

Após a realização dos testes de raiz unitária, a escolha do número de defasagens a ser usada no VAR (PIB, IMP) e no VAR (PIB, IMP, TT) foi feita com base nos

\footnotetext{
${ }^{11}$ De acordo com os testes ADF (0) e PP, para o modelo sem constante e sem tendência, a série das exportações em primeira diferença apresentou uma raiz unitária, ao passo que quando se usa a especificação do teste ADF que adiciona um termo de diferença defasado - ADF (1) - a hipótese nula de raiz unitária é rejeitada a $5 \%$.
} 
critérios Schwarz (SC), Hannan-Quinn (HQ) e Akaike (AIC). ${ }^{12}$ Então, após a escolha do número de defasagens, procedemos à estimação dos dois modelos (VAR) a fim de verificarmos a presença de alguma relação de longo prazo entre as variáveis de cada modelo. Como não foi encontrada nenhuma relação de longo prazo entre as variáveis importações e PIB, e entre as variáveis importações, PIB e termos de troca, foram estimadas duas funções de demanda por importações, para o período 1971-2005, usando a diferença do logaritmo natural de cada variável.

Os resultados da estimação das funções de demanda por importações, ${ }^{13}$ conforme Tabela 1, no Anexo, mostraram que a inclusão da variável termos de troca $-\left(p_{d}-p_{f}-e\right)$ ou $t t-$ na equação de demanda por importações fez subir o valor da elasticidade-renda (de 2,62 para 2,95), apesar de os termos de troca não terem tido significância estatística. Na decomposição da taxa média estimada de crescimento da renda por meio da equação (19), verifica-se, conforme Tabela 2 do Anexo, um crescimento médio anual negativo dos termos de troca (efeito puro dos termos de troca sobre o crescimento da renda real) de 1,86\%. Já o efeito de mudanças exógenas na taxa de crescimento da renda mundial foi de $4,24 \%$, ao passo que o efeito do crescimento das entradas reais de capital foi de $9,82 \%{ }^{14}$. Dessa forma, a taxa média estimada de crescimento da renda conforme o modelo estendido de Thirlwall e Hussain (1982), expresso na equação (19), foi de 4,66\% a.a., enquanto a taxa média observada de crescimento da renda no período 1971-2005 foi de $3,82 \%$ a.a.

Quando se compara a taxa média estimada de crescimento conforme o modelo estendido de Thirlwall e Hussain (1982), que foi de 4,66\% a.a., com a taxa média estimada via regra simples (2,53\% a.a.), conforme Tabelas 2 e 3 do Anexo, verifica-se que a introdução dos termos de troca e dos capitais à regra simples contribuiu para diminuir a diferença entre a taxa média observada de crescimento da renda e a taxa média estimada via regra simples. Assim, enquanto o crescimento médio observado da renda foi de $3,82 \%$ a.a., o crescimento estimado via regra simples foi de $2,53 \%$ a.a., ou seja, uma diferença de $-1,29$ p.p. Mas quando se estima o crescimento via modelo estendido, que inclui termos de troca e capitais, a diferença entre a taxa observada e a taxa estimada cai para 0,84 p.p. Contudo,

\footnotetext{
${ }^{12}$ Resultados não apresentados por conveniência, mas disponíveis sob solicitação.

${ }^{13}$ Em relação a possíveis problemas de quebras estruturais na série estatística de capitais externos quando da não ocorrência significativa de ingressos de capitais (de risco ou de portfólio), vale observar que as possíveis quebras estruturais já foram tratadas de certa forma quando da estimação da função de demanda por importações. Assim, neste trabalho, a estimação das taxas de crescimento da renda brasileira foi feita indiretamente mediante a estimação da função de demanda por importações, que, por sua vez, não leva em conta os capitais externos. É certo que em períodos de menor liquidez externa, menor entrada de capitais, a importação sofrerá quedas, ceteris paribus, podendo até ocorrer quebras. Contudo, tanto as quedas nas taxas de crescimento das importações quanto as possíveis quebras já foram tratadas de certa forma na estimação da função de demanda por importações.

${ }^{14}$ Também para o caso brasileiro, Thirlwall e Hussain (1982) incluíram o fluxo de capitais ao modelo simples para o período 1951-1969 e verificaram que a contribuição desta variável para a diferença entre a taxa estimada e a real foi de $5,4 \%$, enquanto a contribuição dos termos de troca foi de $0,1 \%$.
} 
as taxas observadas (efetiva) e estimada de crescimento da renda ainda apresentam divergências, e este modelo estendido sobre-estimou a taxa média efetiva de crescimento da renda no período 1971-2005.

Para que as taxas estimada e observada de crescimento da renda sejam as mesmas, o valor da elasticidade-renda da demanda (elasticidade hipotética ou de equilíbrio) teria que ser 3,20 e não 2,62, como se verificou na estimação da função de demanda por importações. Mas, quando se estima esta elasticidade-renda real considerando a função de demanda por importações que inclui os termos de troca, verifica-se um valor de 2,95 (apesar de não significativa), conforme Tabela 1 do Anexo. O fato de a elasticidade real ter aumentado e se aproximado da elasticidade hipotética indica a importância de se incluir os termos de troca na função de demanda por importações. No entanto, a inclusão dos termos de troca - utilizando como medida a razão entre o valor unitário das exportações e o valor unitário das importações — não foi significativa no período 1971-2005..$^{15}$

Uma das possíveis causas para a divergência entre as taxas (médias) estimada e observada de crescimento da renda seria o maior crescimento do fluxo real de capitais em relação ao crescimento registrado pelas exportações reais. Conforme Tabela 3 do Anexo, enquanto os capitais cresceram em média 27,33\% a.a., as exportações cresceram em média $6,62 \%$ a.a. no período $1971-2005$. Assim, a maior disponibilidade de recursos externos, advindo do fluxo de capitais, fez com que a taxa estimada de crescimento da renda superasse a taxa estimada compatível com o equilíbrio da conta comercial, expresso pela regra simples.

Ainda considerando o modelo de Thirlwall e Hussain (1982), quando se estima a taxa de crescimento da renda conforme a equação (19), que inclui somente os capitais e não os termos de troca, verifica-se uma taxa média estimada de 5,37\% a.a., ou seja, um valor bem acima da taxa de $2,53 \%$ a.a. (regra simples) e também superior à taxa estimada (4,66\% a.a.) via equação (18), que inclui termos de troca e capitais. Assim, apesar de a elasticidade-preço não ter sido significativa na equação de demanda por importações, na estimação da equação (18) o efeito puro dos termos de troca $(-1,86 \%)$ contribuiu negativamente para o crescimento da renda, ao passo que na estimação da equação (19) esse efeito puro dos termos de troca estava ausente, o que fez com que a taxa estimada apresentasse um maior valor.

Nas estimações das taxas médias de crescimento da renda conforme o modelo de Moreno-Brid (2003) - equações (21) a (23) acima - verifica-se que a divergência entre o crescimento observado da renda no período 1971-2005 e o crescimento estimado via regra simples não foi eliminada. ${ }^{16}$ Assim, considerando a equação (21), que capta a influência do Pagamento Líquido de Juros e assume a hipótese de que o déficit em Conta Corrente como proporção do PIB é estável,

\footnotetext{
${ }^{15} \mathrm{O}$ que sugere, para uma futura pesquisa, o uso de alguma outra medida para os termos de troca (preços relativos), a fim de se verificar a significância estatística desta variável na função de demanda por importações e com o intuito de se incluir os termos de troca na regra simples.

${ }^{16}$ Nas equações (21) a (23) o papel dos termos de troca não está sendo considerado.
} 
conforme Tabela 6 do Anexo, a taxa média estimada de crescimento da renda foi de $2,10 \%$ a.a., valor bem abaixo da taxa média real de crescimento $(3,82 \%$ a.a.), e inferior também à taxa média estimada de $2,53 \%$ a.a. via regra simples.

Uma das possíveis causas para esta baixa taxa estimada seria a influência do Pagamento de Juros sobre as restrições ao crescimento econômico brasileiro no período 1971-2005. Assim, no período inicial de análise, a proporção do Pagamento Líquido de Juros em relação ao gasto com importação representava 9,32\% (ver Tabela 5, do Anexo) e o crescimento real médio do Pagamento Líquido de Juros foi de $9,13 \%$ a.a, o que contribuiu para reduzir a taxa estimada de crescimento da renda neste período de análise. Além disso, outra possível causa para a baixa taxa estimada de crescimento conforme a equação (21) pode estar no fato de se adotar a hipótese de estabilidade do déficit em Conta Corrente como proporção do PIB. No entanto, o déficit em Conta Corrente como proporção do PIB não apresentou nenhum comportamento estável no decorrer do período 1971-2005, de forma que adotar esta estabilidade não seria condizente com os dados analisados para a economia brasileira. ${ }^{17}$

Por outro lado, na estimação do crescimento da renda conforme a equação (22), que considera que o déficit em Conta Corrente é zero, verifica-se uma taxa média de crescimento no valor de $2,63 \%$ a.a., que é bem próxima da taxa média estimada via regra simples, mas se distancia da taxa efetiva média de crescimento da renda. Ademais, como se observa na Tabela 7 do Anexo, quando se calcula a elasticidade-renda hipotética conforme a equação (22), verifica-se um valor de 1,80 , ou seja, uma elasticidade bem próxima à elasticidade-renda hipotética calculada via regra simples.

No entanto, considerar como hipótese para a economia brasileira no período 1971-2005 que o déficit em conta corrente seja zero não é apropriado. Dessa forma, apesar de a taxa média estimada de crescimento da renda segundo a equação (22) ter predito melhor a taxa efetiva média de crescimento - em relação à estimação feita pela equação (21) - não podemos considerar a taxa estimada via equação (22) como sendo a melhor estimativa para o crescimento da renda no período 1971-2005, devido ao fato de que não se pode adotar a hipótese de que o déficit em Conta Corrente foi zero nesse período de análise.

Quando se estima a taxa de crescimento da renda conforme a equação (23), que considera como hipóteses que o Pagamento de Juros é zero e que o déficit em Conta Corrente assume valores não nulos, verifica-se uma taxa média estimada no valor de $2,36 \%$ a.a., que ainda se distancia bastante da taxa efetiva de crescimento e também da regra simples. Por sua vez, a diferença entre a taxa estimada via regra simples e a taxa estimada via equação (23) é que esta última leva em conta a possibilidade de

\footnotetext{
${ }^{17}$ Em Santos et al. (2005), a especificação do modelo de Moreno-Brid (2003) expresso na equação (21) se adequou melhor ao caso brasileiro em relação à regra simples, para o período 1948-2004. Assim, pode ser que adotar a hipótese de estabilidade do déficit em Conta Corrente como proporção do PIB seja razoável em um período mais longo de tempo, como 1948-2004, mas considerar válida esta hipótese para um período mais curto de tempo, como 1971-2005, parece não ser apropriado, como parece indicar nossos dados.
} 
existência de déficits em Conta Corrente, ou seja, admite a possibilidade de que nem todo o gasto com importações seja coberto pelas receitas de exportação.

Assim, conforme a Tabela 5 do Anexo, o fato de que quase $90 \%$ do gasto com importações no período 1971-2005 ter sido coberto pelas receitas de exportação, fez com que a taxa média estimada via equação (23) fosse menor do que a taxa média estimada via regra simples. Se todo o gasto com importações fosse coberto pelas receitas de exportação, estas duas taxas estimadas seriam exatamente iguais, mas como parte do gasto com importações foi coberto pela entrada de capitais, estas taxas médias estimadas não se igualaram.

Mais uma vez, como a taxa média estimada de crescimento da renda via equação (23) se distancia do crescimento observado e, principalmente, dado o fato de estar assumindo como hipóteses que o déficit em Conta Corrente como proporção do PIB é estável e que a entrada de capitais não gera Pagamento Futuro de Juros, ${ }^{18}$ a taxa estimada de crescimento da renda por meio da equação (23) não foi adequada para prever o crescimento brasileiro no período 1971-2005.

\section{CONSIDERAÇÕES FINAIS}

Neste trabalho foi analisada a relação entre a liquidez internacional e o crescimento econômico brasileiro, no período posterior a 1970, conforme abordagem do crescimento econômico com restrições do balanço de pagamentos desenvolvido originalmente por Thirlwall (1979). Muitos trabalhos já haviam testado a chamada regra simples de tal abordagem, quando a conta de capital é suposta constante, e os resultados em geral convergem para a ideia de que as taxas de crescimento estimadas de equilíbrio de balanço de pagamentos são inferiores às taxas de crescimento observadas, o que sempre apontava para o problema de omissão de variáveis tais como os termos de troca ou ainda os fluxos de capitais. Neste trabalho, foi apresentado um modelo analítico que expande teoricamente a regra simples para incorporar tais variáveis. Em seguida, em análises de séries temporais, foram realizadas diversas estimações.

Nossas conclusões empíricas apontam para o fato de que as taxas de crescimento econômico de equilíbrio do balanço de pagamentos quando controladas por variáveis de liquidez internacional mostram-se superiores às taxas observadas. Analiticamente, tais resultados vão ao encontro da ideia de que a economia brasileira apresenta taxas de crescimento maiores em um ambiente de maior liquidez externa, mas não utiliza todo o potencial deste ambiente. Uma hipótese a ser investigada seria a de que grande parte da liquidez externa brasileira seja em forma de empréstimos em moeda - o que pareceu ser o caso no período do "Milagre econômico" — muito mais do que entrada de investimentos diretos ou mesmo investimentos

\footnotetext{
${ }^{18}$ Conforme a Tabela 5 do Anexo, o Pagamento Líquido de Juros Internacionais ao Exterior teve um crescimento anual médio da ordem de 9,13\% no período 1971-2005.
} 
em portfólio. A composição dos fluxos de capitais e seu papel para o crescimento econômico constituem em importante agenda de pesquisa para o futuro.

\section{REFERÊNCIAS BIBLIOGRÁFICAS}

AGHION, Philippe; COMIN, Diego; HOWITT, Peter. (2006) "When does domestic saving matter for economic growth?” NBER Working Paper n. 12275.

BACEN. Base de dados do Banco Central do Brasil. Disponível em http://www.bcb.gov. br/?SERIEBALPAG. Acessado em 19/07/07.

BARBOSA FILHO, N. H. (2001) “The balance-of-payments constraint: from balanced trade to sustainable debt. Banca Nazionale del Lavoro Quartely Review, n. 219.

BIELSCHOWSKY, R. (2000) “Transformação e crise na América Latina e no Caribe, 1950-1984”, in Bielschowsky, R. (org). Cinquenta Anos de Pensamento na CEPAL. Rio de Janeiro: Record, vol. 2.

BRESSER-PEREIRA, L. C. (2006) Macroeconomia da Estagnação: crítica da ortodoxia convencional no Brasil pós-1994. São Paulo: Editora 34.

CANO, Wilson. (2000) Soberania e Política Econômica na América Latina. São Paulo: Editora UNESP.

CASTRO, A. B. de; SOUZA, F. E. P. de. (1985) A Economia Brasileira em Marcha Forçada. Rio de Janeiro: Paz e Terra.

ELLIOTT, D. R.; RHODD, R. (1999) “Explaining growth rate differences in highly indebted countries: an extension to Thirlwall and Hussain”. Applied Economics, 31.

ENDERS, W. (1995) Applied Econometric Time Series. New York: John Wiley \& Sons.

FERREIRA, Alex; CANUTO, Otaviano. (2001) “Thirlwall's law and foreign capital service: the case of Brazil". Workshop on "Macroeconomia Aberta Keynesiana Schumpeteriana: uma Perspectiva Latino Americana”. Unicamp, Campinas, Brazil, June 27-28.

GOURINCHAS, Pierre-Olivier; JEANNE, Olivier (2006). "Capital flows to developing countries: The allocation puzzle”. IMF Working Paper. Disponível em http://www.aeaweb.org/annual_mtg_ papers/2007/0105_1015_0603.pdf. Acessado em 19/07/07.

INTERNATIONAL FINANCIAL STATISTICS. Base de dados IFS. Disponível em http://ifs.apdi.net/ imf/. Acessado em 19/07/07.

IPEA. IPEADATA: dados macroeconômicos e regionais. Disponível em: http://www.ipeadata.gov.br/ ipeaweb.dll/ipeadata?12131968. Acessado em 19/07/07.

JOHANSEN, S.; JUSELIUS, K. (1990) “Maximum likelihood estimation and inference on cointegration - With aplication to the demand fo money". Oxford Bulletin of Economics and Statistics, 52, 169-210.

LIMA, Gilberto Tadeu; CARVALHO, Veridiana Ramos. (2007) “A restrição externa e a perda de dinamismo da economia brasileira: a relação entre estrutura produtiva e crescimento econômico." Informações FIPE, Edição n. 317.

MCCOMBIE, J. S. L.; THIRLWALL A. P. (1994) Economic Growth and the Balance of Payments Constraint. New York: St. Martin's Press;

MCCOMBIE, J. S. L., THIRLWALL A. P. (1997) "Economic growth and the balance-of-payments constraint revisited", in Arestis et al. (eds), Markets, Unemployment and Economic Policy. New York: Routledge.

MENDES, Aldo Luiz. (1993) “A reforma do sistema financeiro nacional”. Estudos Avançados, vol. 7, n.17: 215-220.

MORENO-BRID, J. C. (2003) "Capital Flows, interests payments and the balance-of payments coinstrained growth model: a theoretical and empirical analysis”. Metroeconomica, 54(2). 
Oxford Latin American Economic History Database. Disponível em http://oxlad.qeh.ox.ac.uk/. Acessado em 19/07/07.

SANTOS, A. T. L.; LIMA, G. T.; CARVALHO, V. R. (2005) "A restrição externa como fator limitante do crescimento econômico brasileiro: um teste empírico". Anais Eletrônicos do XXXIII Encontro Nacional de Economia, Natal.

THIRLWALL A. P. (1979) "The balance of payments constraint as an explanation of international growth rates differences”. Banca Nazionale del Lavoro Quarterly Review, 128, pp. 45-53.

THIRLWALL A. P., HUSSAIN M. N. (1982) "The balance of payments constraint, capital flows and growth rates differences between developing countries." Oxford Economic Papers, 34, pp. 498509.

THIRLWALL A. P. (1991) "Professor Krugman's 45-degree rule". Journal of Post Keynesian Economics, Vol. 14, n. 1: 131-147.

THIRLWALL, A. P. (1997) "Reflections on the concept of balance-of-payments-constrained growth". Journal of Post Keynesian Economics, Vol. 19, n. 3.

THIRLWALL A. P. (2005) A Natureza do Crescimento Econômico: Um Referencial Alternativo para Compreender o Desempenho das nações. Brasília, IPEA.

VIEIRA, Fabrício de Assis Campos. (2007) Crescimento Econômico Secular no Brasil: uma investigação empírica a partir da abordagem do crescimento com restrição externa. Dissertação (Mestrado), IE-UFU.

ANEXO — TABELAS DE RESULTADOS

Tabela 1: Funções de demanda por importações: In $m=a+\pi(\operatorname{In} y)+\psi(\operatorname{In} t t) 1971-2005$

\begin{tabular}{|c|c|c|c|c|}
\hline & Constante & Elasticidade-renda & Elasticidade-preço & DW \\
\hline Sem $t t$ & $\begin{array}{c}-0,0673 \\
(-1,86)\end{array}$ & $\begin{array}{c}2,6203 \\
(4,63)\end{array}$ & - & 1,28 \\
\hline Com $t t$ & $\begin{array}{c}-0,0737 \\
(-2,04)\end{array}$ & $\begin{array}{c}2,9550 \\
(5,07)\end{array}$ & $\begin{array}{c}-0,1912 \\
(-1,13)\end{array}$ & 1,5 \\
\hline
\end{tabular}

Notas: Os números entre parêntese indicam os t-values. Foram incluídas dummies para os anos 1974 e 1985 e uma step dummy para 1988-1998; os testes de normalidade e estacionariedade indicaram que os resíduos são normais e estacionários.

Fonte: Elaboração própria com IPEADATA e Oxford Latin American Economic History Database.

Tabela 2: Decomposição da taxa estimada de crescimento da renda e taxa estimada média de crescimento segundo o modelo expandido de Thirlwall e Hussain (1982)

que inclui termos de troca e fluxo de capitais - 1971-2005

\begin{tabular}{|c|c|c|c|c|}
\hline $\begin{array}{l}\text { Efeito do volume das } \\
\text { alterações nos termos } \\
\text { de troca } \\
(\theta \eta+\Psi)\left(p_{d}-p_{f}-e\right)\end{array}$ & $\begin{array}{l}\text { Efeito puro } \\
\text { dos termos } \\
\text { de troca } \\
\left(p_{d}-p_{f}-e\right)\end{array}$ & $\begin{array}{c}\text { Efeito de mudanças } \\
\text { exógenas na taxa de } \\
\text { crescimento da renda } \\
\text { internacional } \\
\theta(x)\end{array}$ & $\begin{array}{c}\text { Efeito do } \\
\text { crescimento das } \\
\text { entradas reais } \\
\text { de capital } \\
(1-\theta)\left(f-p_{d}\right)\end{array}$ & $\begin{array}{c}\text { Taxa estimada } \\
\text { de crescimento } \\
\text { segundo } \\
\text { modelo } \\
\text { estendido (\%) } \\
y_{b t h}\end{array}$ \\
\hline N.A* & $-1,86$ & 4,24 & 9,82 & 4,66 \\
\hline
\end{tabular}

Notas: * O efeito do volume das alterações nos preços relativos é inexistente devido ao fato de que a elasticidade-preço da demanda por importações $(\psi)$ não foi significativa na função de demanda por importações, e porque assumiu-se que a elasticidade-preço da demanda por exportações $(\eta)$ é irrelevante, pois $\varepsilon(z)=x$ na função de demanda por exportações.

Fonte: Estimativa própria com IPEADATA, Oxford Latin American Economic History Database e Banco Central do Brasil. 
Tabela 3: Taxa Anual média de crescimento da renda, das exportações e do fluxo real de capitais, e taxas estimadas médias usando a "regra simples" e o modelo expandido de Thirlwall e Hussain (1982) que inclui a variável fluxo de capitais - 1971-2005

\begin{tabular}{|c|c|c|c|c|c|}
\hline $\begin{array}{c}\text { Crescimento } \\
\text { da renda (\%) } \\
(y)\end{array}$ & $\begin{array}{c}\text { Crescimento das } \\
\text { exportações (\%) } \\
(x)\end{array}$ & $\begin{array}{c}\text { Elasticidade-renda } \\
\text { da demanda por } \\
\text { importações (\%) } \\
(\pi)\end{array}$ & $\begin{array}{c}\text { Taxa estimada } \\
\text { segundo a } \\
\text { regra simples” (\%) } \\
y_{b}=x / \pi\end{array}$ & $\begin{array}{c}\text { Crescimento } \\
\text { do fluxo real } \\
\text { de capitais } \\
(\%) \\
(f)\end{array}$ & $\begin{array}{c}\text { Taxa estimada } \\
\text { segundo o } \\
\text { modelo estendi- } \\
\text { do que inclui os } \\
\text { capitais }(\%) \\
\left(y_{b t b^{*}}\right)\end{array}$ \\
\hline 3,82 & 6,62 & 2,62 & 2,53 & 27,33 & 5,37 \\
\hline
\end{tabular}

Fonte: Estimativa própria com base em dados do IPEADATA, Oxford Latin American Economic History Database e Banco Central do Brasil.

Tabela 4: Elasticidade-renda real da demanda por importações e elasticidades-renda hipotéticas calculadas através dos modelos expandido de Thirlwall e Hussain (1982) e "regra simples" - 1971-2005

\begin{tabular}{|c|c|c|c|}
\hline $\begin{array}{c}\text { Elasticidade- } \\
\text { renda real } \\
(\pi)\end{array}$ & $\begin{array}{c}\text { Elasticidade-renda hipotética } \\
\text { conforme modelo estendido } \\
\text { que inclui termos de troca e } \\
\text { fluxo de capitais } \\
\left(y_{b t b}\right)\end{array}$ & $\begin{array}{c}\text { Elasticidade-renda hipotética } \\
\text { conforme modelo estendido } \\
\text { que inclui somente fluxo de } \\
\text { capitais } \\
\left(\pi_{m b^{*}}\right)\end{array}$ & $\begin{array}{c}\text { Elasticidade-renda } \\
\text { hipotética conforme } \\
\text { "regra simples" } \\
\left(\pi_{b^{*}}\right)\end{array}$ \\
\hline 2,62 & 3,20 & 3,69 & 1,74 \\
\hline
\end{tabular}

Fonte: Estimativa própria com base em dados do IPEADATA, Oxford Latin American Economic History Database e Banco Central do Brasil.

Tabela 5: Taxas anuais médias de crescimento das importações e do pagamento de juros, e gasto com importação coberto pelas receitas de exportação e pagamento de juros em relação ao gasto com importação, segundo o modelo de Moreno-Brid (2003) - 1971-2005

\begin{tabular}{|c|c|c|c|}
\hline $\begin{array}{c}\text { Crescimento das } \\
\text { importações (\%) } \\
(m)\end{array}$ & $\begin{array}{c}\text { Crescimento do } \\
\text { pagamento } \\
\text { de juros (\%) } \\
(d r / r)\end{array}$ & $\begin{array}{c}\text { Gasto com importação } \\
\text { coberto pelas receitas } \\
\text { de exportação (\%) } \\
\left(\theta_{1}\right)\end{array}$ & $\begin{array}{c}\text { Pagamento de Juros em } \\
\text { relação ao gasto com } \\
\text { importação (\%) } \\
\left(\theta_{2}\right)\end{array}$ \\
\hline 5,27 & 9,13 & 89,42 & 9,32 \\
\hline
\end{tabular}

Fonte: Estimativa própria com base em dados do IPEADATA, Oxford Latin American Economic History Database e Banco Central do Brasil. 
Tabela 6: Taxa anual média de crescimento da renda (em porcentagem),

e taxas estimadas médias de crescimento (em porcentagem) usando os modelos expandido de Moreno-Brid (2003) e a "regra simples" - 1971-2005

\begin{tabular}{|c|c|c|c|c|}
\hline $\begin{array}{c}\text { Crescimento } \\
\text { da renda } \\
(y)\end{array}$ & $y_{m b}=\frac{\theta_{1} d x / x-\theta_{2} d r / r}{\pi-\left(1-\theta_{1}+\theta_{2}\right)}$ & $y_{m b^{*}}=\frac{\theta_{1} d x / x+\left(1-\theta_{1}\right) d r / r}{\pi}$ & $y_{m b^{* *}}=\frac{\theta_{X M} d x / x}{\pi-\left(1-\theta_{X M}\right)}$ & $y_{b^{*}}=\frac{\frac{d x}{x}}{\pi}$ \\
\hline 3,82 & 2,10 & 2,63 & 2,36 & 2,53 \\
\hline
\end{tabular}

Fonte: Estimativa própria com base em dados do IPEADATA, Oxford Latin American Economic History Database e Banco Central do Brasil.

Tabela 7: Elasticidade-renda real da demanda por importações e elasticidades-renda hipotéticas calculadas através dos modelos expandido de Moreno-Brid (2003) e "regra simples" - 1971-2005

\begin{tabular}{|c|c|c|c|c|}
\hline $\begin{array}{c}\text { Elasticidade- } \\
\text { renda real } \\
(\pi)\end{array}$ & $\begin{array}{c}\text { Elasticidade- } \\
\text { renda hipotética } \\
\text { conforme modelo } \\
\text { estendido } \\
\left(\pi_{m b}\right)\end{array}$ & $\begin{array}{c}\text { Elasticidade-renda } \\
\text { hipotética conforme } \\
\text { modelo estendido } \\
\left(\pi_{m b^{*}}\right)\end{array}$ & $\begin{array}{c}\text { Elasticidade-renda } \\
\text { hipotética } \\
\text { conforme modelo } \\
\text { estendido } \\
\left(\pi_{m b^{* *}}\right)\end{array}$ & $\begin{array}{c}\text { Elasticidade-renda } \\
\text { hipotética conforme } \\
\text { "regra simples" }\end{array}$ \\
\hline 2,62 & 1,52 & 1,80 & 1,84 & $\left(\pi_{b^{*}}\right)$
\end{tabular}

Fonte: Estimativa própria com base em dados do, IPEADATA, Oxford Latin American Economic History Database e Banco Central do Brasil. 